\title{
The Impact of COVID-19 Lockdown on Portuguese Households' Food Waste Behaviors
}

\author{
Iva Miranda Pires ${ }^{1}$ \\ Interdisciplinary Center of Social Sciences (CICS.NOVA), Faculty of Social Sciences \\ and Humanities (FCSH/NOVA), NOVA University of Lisbon, Portugal \\ María Ángeles Fernández-Zamudio \\ Centro para el Desarrollo de la Agricultura Sostenible (CDAS), Instituto Valenciano \\ de Investigaciones Agrarias, Valencia, Spain \\ Berta Vidal-Mones \\ Center for Agro-Food Economy and Development (CREDA-UPC-IRTA), Barcelona, Spain \\ Rita Beltrão Martins \\ Centre for the Research and Technology of Agro-Environmental and Biological Sciences \\ (CITAB), and Centro de Química-Vila Real, Universidade de Trás-os-Montes e Alto Douro
}

\section{Abstract}

On March 19, 2020, a State of Emergency was declared in Portugal as a way to contain the spread of the COVID-19. Restriction measures were adopted, limiting the mobility of the population.

This paper presents preliminary results of an online survey to Portuguese households on the impact of COVID-19 lockdown on food purchase, storage, management, and waste generation. A total of 841 questionnaires were collected.

The main changes observed were in food purchasing behavior, as 77 percent stated that they had reduced the frequency of grocery shopping, and 68 percent had bought more in local shops than before. Regarding food waste generation, the majority (60 percent), stated that during lockdown they threw away the same amount of food as before. 36 percent answered less than before, reporting that they had adopted strategies to reduce food waste. Vegetables, milk, and fruit were the goods with the highest reduction of food waste.

Keywords: COVID-19, food management, households, lockdown

1 Corresponding author: im.pires@fcsh.unl.pt. 


\section{Introduction}

COVID-19 is the infectious disease caused by the most recently discovered coronavirus. In Europe, cases began to be detected from late January 2020 and the infection spread rapidly, affecting all countries to a greater or lesser extent. Portugal's first cases were detected on March 2, with two Portuguese citizens arriving from Italy. On March 11, the World Health Organization declared COVID-19 a global pandemic.

In this initial phase, as the virus spread around the world, Portugal decreed a State of Emergency, with three fortnightly periods of containment, which took place between March 19 and May 2, 2020. On May 3, the State of Calamity replaced the State of Emergency, allowing a gradual and slow reopening of the economy. From September 15, the State of Emergency was enforced again, to prepare for a second wave of the outbreak but lockdown was not applied_- just the recommendation to stay at home and telework whenever possible.

There were only three deaths by COVID-19 (and 785 cases) recorded in Portugal when the first State of Emergency was declared on March 19, imposing restrictions on circulation in public spaces. Citizens were confined at home, allowed to leave only for health reasons, purchase of goods and services, family support, professional activities (whenever it was not possible to use telework), and short trips for the purposes of physical activity and pet walking. Recreational, cultural, sports, and catering activities and retail trade-except for those selling essential goods-were closed. In education, universities were the first to close, switching to online learning, followed closely by all other schools.

We present the results of an online survey to Portuguese households to understand how the lockdown affected their purchasing habits, food storage, and waste generation, together with how families perceived these changes. This survey was also carried out in Spain, Germany, and Ecuador, and was prepared by a group of professionals from the agrifood sector, research centers, universities, and other institutions from different countries, which created a network about food loss and waste (FLW) named "Red Sin Desperdicio."

\section{Food loss and waste}

The issue of food is highly relevant for human ecology. As Valera (2014) argues, it intercepts the three directions of the human relationship-the one they build with the environments in which they live, the one the individual human being interweaves with other human beings, and the one that every human individual builds in dialogue with himself or herself. On the other hand, the way food is 
nowadays produced, processed, distributed, consumed, discarded, and finally treated is dynamic, creating externalities and environmental, health, economic and social costs. Food losses and waste (FLW) is an inefficiency of global food systems (Willett et al., 2019), and its reduction is part of the solution for a transition to more sustainable food systems (Benton \& Bailey, 2019).

In Portugal, we waste about a million tons of food every year along the food supply chain. This equals roughly 17 percent of all food produced for human consumption in Portugal; of that million tons of waste, households contribute around 32 percent (Baptista et al., 2012).

The data for Portugal is not particularly good, considering that the country is not self-sufficient in food production; in some products, the level of self-provisioning is only 20 percent and imports are needed to meet demand. Besides that, in some parts of the country soil erosion and lack of water threatens the ability to produce food; a situation that will be aggravated with climate change. On top of that, according to the National Food, Nutrition and Physical Activity Survey 2015-2016 (Lopes et al., 2017), the prevalence of food insecurity was 10.1 percent among the Portuguese population.

All this points to the urgency to reduce FLW in Portugal, especially at the latter stages of the food supply chain, such as households, where environmental, social, and economic impacts are higher.

Reducing FLW in households implies changing behaviors, attitudes, routines, and collective consumers' culture (Evans, 2011, 2014; Schanes, et al., 2018). FLW is usually a result of the interaction between multiple behaviors that occur at different moments of dealing with food, such as planning, shopping, storage, preparation, consumption, leftovers management, and assessment of suitability for consumption before being thrown away (Hebrok \& Heidenstrøm, 2019). The importance given to aesthetics, routines, family dynamics, and shopping location (Dobernig \& Schanes, 2019; Lee, 2018) are key factors that contribute to explaining a greater or lesser amount of FLW. Other less-studied factors influencing FLW generation in households are price and dietary importance (Diaz-Ruiz et al., 2018). Current food chains mainly lead by mega-retailers aim at economic efficiency, providing customers with a wide choice of cheap, high-quality goods and services, which makes it easy to purchase food without requiring much organization or planning. However, these convenient mega-retailer chains hide enormous environmental and social impacts (Christensen, 2015). The author argues that having more time would help people consume in a more political way, for instance, purchasing in local shops or farmer's markets, or using less plastics by buying bulk and local products (Christensen, 2015). Planning for purchases and making meal plans are other practices of organizing temporality that can contribute to avoiding food ending up as waste (Mattila et al., 2018). 
During lockdown, the routines associated with food purchasing, stocking, preparation, and consumption changed dramatically, with most meals being consumed at home. This scenario raised some questions: Which strategies were adopted by families to cope with and adapt to the new reality? Did they change their purchasing practices? Did they purchase more food? At local grocery shops or in large supermarkets? Did they shop online more than before? Did they order takeaway more often than before? And what was the impact of all this in household food waste?

\section{Methodology}

A survey was carried out in Portugal, Spain, Germany, and Ecuador, between May 14 and June 11,2020, coordinated by Red Sin Desperdicio, to which all the authors belong. The members of Red Sin Desperdicio participate in international networks on FLW, and during the preparation and design of the survey have collaborated with similar initiatives that were being carried out in the United Kingdom by WRAP, in the Netherlands by the University of Wageningen, and in Italy by the University of Bologna.

An online questionnaire, composed of 36 questions and about 10 minutes' length, was rapidly distributed, addressing households in Portugal. Since the sample is non-probabilistic, we cannot say that the respondents are a faithful reflection of all the social strata in Portuguese society, but rather the response given by a part of the population who received the survey through social networks, institutional mailings, or from other organizations.

In Portugal, the survey was carried out between May 22 and June 5 (around three weeks after the end of the third State of Emergency, on May 1). A total of 841 valid questionnaires were collected from all regions, except Azores, with Lisbon and Oporto Metropolitan areas the most relevant groups, representing 39 percent of the answers.

The questionnaires were filled out mostly by women (71 percent), aged 19 to 76 , and the rest by men aged 23 to 84 . This gender bias in food- and cooking-related surveys is common and our current results are in line with what is indicated by work in Tunisian (Jribi et al., 2020) and Dutch households (van der Haar et al., 2020).

2 The Waste and Resources Action Programme (operating as WRAP). 


\section{Main results and discussion}

Different authors report that when any type of crisis occurs, there are changes in attitudes towards how food is acquired or managed (Fanelli \& Di Florio, 2016; Martinengo, 2014) and, by extension, an increase in waste is also to be expected.

The results of our online survey indicated that the main changes were observed in food purchasing behavior. However, in Portugal, these changes did not translate into an increase in online shopping, which had been observed in other countries that applied the same survey, but rather a reduction in the frequency of purchases, and much more shopping in local shops than before. Of the overall number of respondents, less than half ( 45 percent) responded that they did not buy more than usual during confinement. Next, when asked why they might buy more, only 24 percent said they were afraid or anxious. Thus, storing more food could be a consequence of having the family eating all meals at home, together with the mobility restrictions, so the need to store more food than usual might not be out of fear or anxiety, similar to what led consumers to rush into supermarkets, stockpiling nonperishable items at the beginning of confinement.

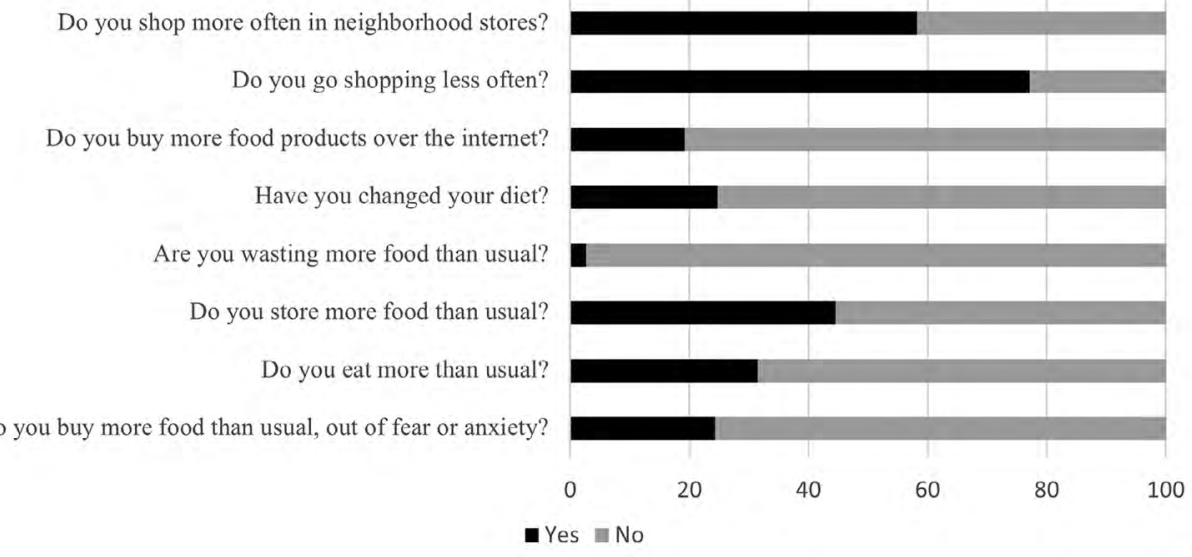

Figure 1. Survey responses to the question, "Please indicate whether you recognize some of these behaviors since lockdown started."

Source: Authors' summary of survey results.

A sudden increase in online shopping is one of the changes in purchasing behaviors associated with COVID-19, which had been reported in several countries. Online grocery shopping emerged as the pandemic spread, attracting new customers not used to purchasing from home (Charlebois, 2020). This change could be relevant: online shopping is more likely to push consumers to make more intentional choices, and to stick to their planned shopping list, therefore avoiding unnecessary purchases, which can potentially contribute to food waste reduction (Mattila et al., 2018). 
Only 20 percent of survey respondents said that during lockdown they bought more food online than usual, but 77 percent stated that they reduced the number of times they went shopping (in another national survey, ${ }^{3} 71$ percent confirmed changes in the frequency of shopping) and almost 60 percent indicated buying more now in nearby grocery shops. These results coincide with those of other studies conducted in other countries during the lockdown (Jribi et al., 2020; Roberts \& Downing, 2020; van der Haar et al., 2020).

Respondents said they were more careful when shopping; 30 percent prepared a shopping list more than in the past and only 2.6 percent said they used a shopping list less than before. Nevertheless, 58 percent admitted to maintaining their level of impulse purchases, buying goods that were not planned, and only a minority said this happened less than previously.

Respondents also stated (75.3 percent) they did not change their usual diets. Nevertheless, a survey from the National Health Service about changes in food consumption behaviors among Portuguese consumers during lockdown reported the following variations: an increase in water consumption (31.1 percent), in sweet snacks (30.9 percent), in fruit (29.7 percent) and in vegetables (21.0 percent). On the other hand, this official study registered a decrease in takeaway consumption (43.8 percent), precooked meals (40.7 percent), soft drinks (32.8 percent) and alcoholic beverages ( 28.2 percent) — practices associated with a more healthy way of eating (National Health Service, 2020, p. 6).

Proceeding with our survey analysis, 97 percent of the respondents stated that they did not waste more food than before and have adopted food management behaviors more often than before COVID-19. Some of the main changes reported were: 25 percent said they prepared creative and different recipes to take advantage both of all food leftovers and all edible parts of food; 13 percent affirmed they adjusted the amount of cooked food to what was actually going to be consumed; 10 percent mentioned they organized food by expiration date, to be aware of what to eat first; 9 percent affirmed they checked the fridge to monitor the state of stored food; and 6 percent said if they had leftovers, it would be used in another meal.

Eating at home more frequently, and buying more food, are the main reasons pointed out by those who admitted wasting more food during lockdown. On the other hand, those who mentioned wasting less gave the following reasons: making better use of leftovers (19 percent), cooking more efficiently (14 percent), and having less unpredictable situations (11 percent).

3 Cross-sectional observational study, with a non-probabilistic baseline sample of individuals aged 16 or more in situation of quarantine at home due to the COVID-19 pandemic. Data collection (5,874 respondents) was carried out during the period of confinement, between 04 April, 2020 and 04 May, 2020 (National Health Service (Serviço Nacional de Saúde), 2020). 
Another consequence of confinement was the fall in demand for hospitality products, and the consequences this could have for increasing the overall generation of FLW in the food chain. In Portugal in particular, producers' associations reported that they had been forced to discard large quantities of food, namely perishable products such as fruit, vegetables, and milk, during the outbreak, due to the cancellation of purchases in food services and supermarkets (Mateus, 2020).

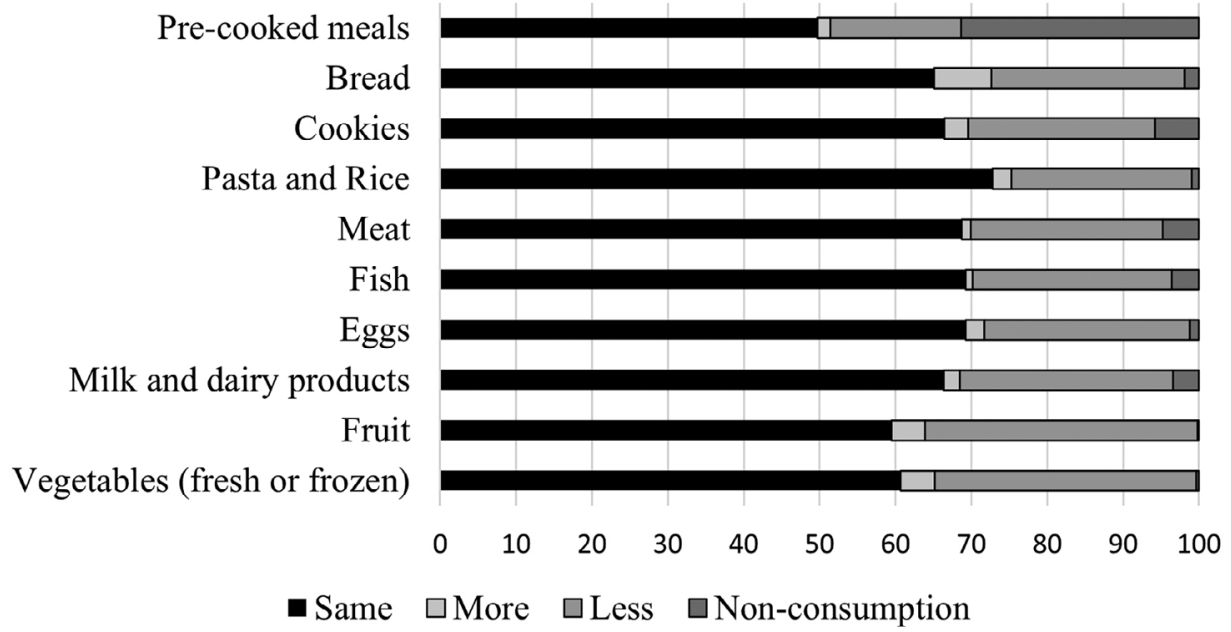

Figure 2. Survey responses to the question, "Regarding these foods, did you throw away more or less quantity during confinement?"

Source: Authors' summary of survey results.

The type of food bought may also be related to the amount of food that is wasted: the shelf life of different foods varies a lot, and when it comes to storing them at home, the best means of avoiding waste are not always available. In our survey we found that during lockdown, respondents did not change the type of food they were already throwing away, but reduced the amount between 25 percent to 36 percent, the majority being perishable goods. As an example, the reduction in fruit waste represented 36 percent, while for vegetables, 34.5 percent (Figure 2). These savings resulted from more careful management of the available food, as already discussed.

This decrease in FLW could be a result of having more time at home, which allowed better planning and organization of the tasks associated with food, giving more efficient use of the food available at home. Staying at home implies having more time, which could be used to better plan the shopping list and meals, something already confirmed in previous studies (Mattila et al., 2018). In our study, those who answered that they perceived they were wasting less mentioned: "We spend more time at home, so there is more time and a willingness to cook;" "We cook more efficiently;" "I cook food for longer so that food has more flavor;" and "We make the most of leftovers." When asked if they could estimate the amount of food that is 
wasted per week, one out of two respondents said yes. But only 44 percent mentioned a value, and of these 28 percent said they waste less than 30 grams per week, even in the case of families with five members. Even if households have a positive perception that during lockdown they have reduced their food waste, that perception, when related to the amounts they are still generating, is far from the real numbers.

Having more time at home for planning and cooking, being aware of stored food and leftovers, and storing products according to their expiration dates, are some of the habits that Portuguese households implemented during the lockdown. Surely, having more time to think and act regarding food may have raised awareness of the environmental, economic, and social impacts of what we consume, leading to more responsible behaviors. If so, the perceived food waste reduction among Portuguese households may have reduced the environmental, social, and economic impacts of the food being lost or wasted at the consumer stage.

\section{Conclusion}

Based on Portuguese survey results, COVID-19 lockdown lead to a positive perception of behavior change regarding food waste. In spite of the fact that some respondents have maintained their impulse purchases, respondents said they have planned meals more in advance, and used a shopping list more often than before, from which a positive change in behavior on daily food consumption can be deduced. During this period, respondents shopped more frequently in local shops, and considerably reduced the frequency of grocery shopping visits. Some respondents mentioned reducing grocery shopping trips in order to prevent the risk of infection, creating room for new household strategies of food management, thus indirectly leading to a decrease in food waste. Apart from better shopping planning and using shopping lists, they also mentioned using leftovers to prepare new meals, using all edible parts of food, and adjusting the amount of food cooked to what was actually going to be consumed. Better food organization according to expiry dates, together with regular fridge monitoring to check the state of stored food, were also strategies adopted. As a result, 25 percent to 36 percent of the respondents have reported being successful in reducing food waste, in particular fruit and vegetables.

In conclusion, a problem as serious and global in scope as COVID-19 seems to be showing that it could contribute to reducing FLW. A change in conventional consumption models is essential, and adopting responsible consumption of food seems to be approachable. For this, the practices of buying, preserving, cooking, and consuming food at home have to change. Despite this, some questions remain unanswered: Will consumers' food behaviors observed during lockdown persist in the future? Or is this change in behavior just a belief of those who responded to the surveys, and these best practices will not have a real impact, nor be consolidated 
in the future? We would like to think that there are a number of positive learnings resulting from this pandemic, but this is something we can only confirm with future studies.

\section{Acknowledgement}

This work is financed by national funds through FCT-Foundation for Science and Technology, I.P., within the scope of the project UIDB / 04647/2020 of CICS.NOVA - Centro Interdisciplinar de Ciências Sociais da Universidade Nova de Lisboa.

\section{References}

Baptista, P., Campos, I., Pires, I., \& Vaz, S. (2012). Do Campo ao Garfo. Desperdício Alimentar em Portugal, Lisboa [From the field to the fork: Food waste in Lisbon, Portugal]. CESTRAS.

Benton, T. G., \& Bailey, R. (2019). The paradox of productivity: Agricultural productivity promotes food system inefficiency. Global Sustainability, 2, e6. doi.org/10.1017/sus. 2019.3

Charlebois, S. (2020, March 26). Why COVID-19 will change Canadian grocery industry forever. Retail Insider E-News. www.retail-insider.com/retail-insider/2020/3/why-covid19-will-change-the-food-industry-forever

Christensen, C. B. (2015). Two kinds of economy, two kinds of self-toward more manageable, hence more sustainable and just supply chains. Human Ecology Review, 21(2), 3-22. doi.org/10.22459/her.21.02.2015.01

Diaz-Ruiz, R., Costa-Font, M., \& Gil, J. M. (2018). Moving ahead from food-related behaviours: An alternative approach to understand household food waste generation. Journal of Cleaner Production, 172, 1140-1151. doi.org/10.1016/j.jclepro.2017.10.148

Dobernig, K., \& Schanes, K. (2019). Domestic spaces and beyond: Consumer food waste in the context of shopping and storing routines. International Journal of Consumer Studies, 43(5), 480-489. doi.org/10.1111/ijcs. 12527

Evans, D. (2011). Blaming the consumer-once again: The social and material contexts of everyday food waste practices in some English households. Critical Public Health, 21(4), 429-440. doi.org/10.1080/09581596.2011.608797

Evans, D. (2014). Food waste: Home consumption, material culture and everyday life. Bloomsbury Academic.

Fanelli, R. M., \& Di Florio, A. (2016). Domestic food waste, gap in times of crisis. Italian Review of Agricultural Economics, 71(2), 111-125. doi.org/10.13128/REA-20075 
Hebrok, M., \& Heidenstrøm, N. (2019). Contextualising food waste prevention-Decisive moments within everyday practices. Journal of Cleaner Production, 210, 1435-1448. doi.org/10.1016/j.jclepro.2018.11.141

Jribi, S., Ben Ismail, H., Doggui, D., \& Debbabi, H. (2020). COVID-19 virus outbreak lockdown: What impacts on household food wastage? Environment, Development and Sustainability, 22, 3939-3955. doi.org/10.1007/s10668-020-00740-y

Lee, K. C. L. (2018). Grocery shopping, food waste, and the retail landscape of cities: The case of Seoul. Journal of Cleaner Production, 172, 325-334. doi.org/10.1016/ j.jclepro.2017.10.085

Lopes, C., Torres, D., Oliveira, A., Severo, M., Alarcão, V., Guiomar, S., ... Ramos, E. (2017). Inquérito Alimentar Nacional e de Atividade Fisica, IAN-AF 2015-2016: Relatório de resultados [National food, nutrition and physical activity survey, 2015-2016]. Universidade do Porto. ian-af.up.pt/sites/default/files/IAN-AF\%20Relat\%C3\%B3rio\%20 Resultados_0.pdf

Martinengo, M. C. (2014). Household food waste and consumer culture: Reflections on Italian behaviour. Journal of Nutritional Ecology and Food Research, 2(1), 73-77. doi.org/ 10.1166/jnef.2014.1062

Mateus, C. (2020, May 16). Covid-19. Toneladas de alimentos estão a ser deitados ao lixo. E nem a cerveja escapa [COVID-19. Tons of food are being thrown away. And not even the beer escapes]. Expresso. expresso.pt/economia/2020-05-16-Covid-19.-Toneladasde-alimentos-estao-a-ser-deitados-ao-lixo.-E-nem-a-cerveja-escapa

Mattila, M., Mesiranta, N., Narvanen, E., Koskinen, O., \& Sutinen, U-M. (2018). Dances with potential food waste: Organising temporality in food waste reduction practices. Time \& Society, 28(4), 1619-1644. doi.org/10.1177/0961463x18784123

National Health Service (Serviço Nacional de Saúde). (2020). REACT-COVID, Inquérito sobre alimentação e atividade fisica em contexto de contenção social [REACT-COVID: Survey on food and physical activity in the context of social containment] [Survey report]. www. dgs.pt/programa-nacional-para-a-promocao-da-atvidade-fisica/ficheiros-externos-pnpaf/ rel_resultados-survey-covid-19-pdf.aspx

Roberts, M., \& Downing, P. (2020). Citizen responses to the COVID-19 lockdown-Food purchasing, management and waste. WRAP. wrap.org.uk/sites/default/files/2020-10/ WRAP-Citizen_responses_to_the_Covid-19_lockdown_0.pdf

Schanes, K., Dobernig, K., \& Gozet, B. (2018). Food waste matters-A systematic review of household food waste practices and their policy implications. Journal of Cleaner Production, 182(1), 978-991. doi.org/10.1016/j.jclepro.2018.02.030

Valera, L. (2014). Human ecology and food. Encyclopedia of food and agricultural ethics. Springer. doi.org/10.1007/978-94-007-6167-4_168-1 
van der Haar, S., Zeinstra, G., Bos-Brouwers, H., \& Janssen, A. (2020). COVID-19 and the effects on Dutch consumers' food waste behavior [Survey report]. Wageningen University. www.wur.nl/upload_mm/1/6/3/c0927cca-db6e-441c-ac25-8fe8c9c87ade_200702\%20 Results\%20Covid19\%20Food\%20Waste\%20study\%20FINAL.PDF

Willett, W., Rockström, J., Loken B., Springmann M., Lang, T., Vermuelen, S., ... Murray, C. J. L. (2019). Food in the Anthropocene: The EAT-Lancet Commission on healthy diets from sustainable food systems. The Lancet, 393(10170), 447-492. dx.doi.org/10.1016/ S0140-6736(18)31788-4 
This text is taken from Human Ecology Review, Volume 26, Number 1, 2020, published by ANU Press, The Australian National University, Canberra, Australia. doi.org/10.22459/HER.26.01.2020.06 